\title{
Proceeding
}

Supplementary Issue: Summer Conferences of Sports Science. Costa Blanca Sports Science Events, 25-26 September 2020. Alicante, Spain.

\section{Design and teaching of physical education for children and youth}

\author{
FRANCESCA D'ELIA ${ }^{1} \triangle$, PATRIZIA TORTELLA² ${ }^{2}$ ITALO SANNICANDRO ${ }^{3}$, TIZIANA D'ISANTO ${ }^{1}$ \\ 1 University of Salerno, Italy \\ ${ }^{2}$ Free University of Bozen, Italy \\ 3 University of Foggia, Italy
}

\begin{abstract}
The reduction of physical activity is a phenomenon that affects the world population at all ages (childhood and adolescence, adulthood and third age) whose effects do not only concern the predisposition to risk factors for health but also more generally well-being and good individual bio-psycho-social functioning. Sedentary lifestyle, unfortunately, no longer affects adults and the elderly, but it is an unhealthy habit that is grafted more and more precociously, also extending to children and adolescents. In fact, during the developmental age we observe alarming trends of involution of motor skills with a general trend of reduction in the quality and quantity of movements in both children and adolescents; over the last fifty years, unfortunately, the coordination of school-age children has regressed, manifesting itself with a significant delay in the development of coordination especially in urban populations, as well as being affected by a serious and widespread problem of overweight and obesity in age paediatric. This paper analyses some special educational needs of movement during childhood and adolescence, even in the presence of disabilities, and tracks the main teaching methods that enhance the body and movement and the sensory perceptive system. Keywords: Needs of moving; Physical inactivity trends; Teaching methods.
\end{abstract}

\section{Cite this article as:}

D'Elia, F., Tortella, P., Sannicandro, I., \& D'Isanto, T. (2020). Design and teaching of physical education for children and youth. Journal of Human Sport and Exercise, 15(4proc), S1527-S1533. doi:https://doi.org/10.14198//hse.2020.15.Proc4.48

Corresponding author. University of Salerno, Italy.

E-mail: fdelia@unisa.it

Abstract submitted to: Spring Conferences of Sports Science. Costa Blanca Sports Science Events, 19-20 June 2020. Alicante, Spain.

JOURNAL OF HUMAN SPORT \& EXERCISE ISSN 1988-5202

(c) Faculty of Education. University of Alicante

doi:10.14198/jhse.2020.15.Proc4.48 


\section{NEEDS OF MOVING}

Movement is one of the main functions of the human body. Through the body and the movement and the body in movement it is possible to carry out development, improvement, maintenance and conservation of the body's functions and structures (WHO, 2001). Movement produces effects on all functions of the body and its practice or deficiency affects the whole person with different effects depending on the different stages of life.

During childhood and adolescence movement mainly plays a development role; this stage of life, compared to the subsequent stages (adulthood and elderly), is characterized by a greater aptitude for changes and greater readiness for learning. In particular, they are fundamental the structuring of functional prerequisites of movements (body scheme, balance, laterality, coordination, space-time organization, postural tone, relaxation, etc.) and the development and consolidation of motor skills (motor milestones and specific motor skills). The effects of movement are not just about the motor skills but also about the cognitive, emotional, relational and social areas of human functioning. When we move and practice physical and sport activity we develop, stimulate and improve the functionality of the afferent sensory pathways, with a consequent increase in cognitive processing, and we promote the development of cognitive functions at elementary (attention and memorization), intermediate (analysis, processing, choice) and higher level (intuition, convergent and divergent thinking). An extensive scientific literature confirms the relationship between body, movement and learning processes: active pedagogy founded teaching on the experiential and sensorimotor dimension (Dewey, 1961, Montessori, 1950); psychomotor approach considers body and movement as vehicles of affective, cognitive and relational experiences (Wallon); the genetic epistemology highlights the value of physical knowledge which can be gained through their perceptual properties (Piaget, 1972); the multiple intelligences theory by H. Gardner (1983) and the emotional approach of D. Goleman (1995), have contributed to a recognition of the bodily-kinaesthetic dimension as the basis of some learning, to the identification of a plurality of independent but strongly interacting formae mentis, to the re-evaluation of an emotional mind able to influence our actions. The metacognitive studies of Ausbel (2004) and Novak (2001) have constantly underlined the importance of the interaction between thought (cognition), feelings (emotions) and actions. On a philosophical perspective, Maurice Merleau Ponty's (2003) reading of the relationships between the biological, psychological and social dimensions allowed for an analysis of the relationships between physical activity and social models, identifying in "body and movement" precious tools for mediation and communication with the world. Recent neuro-bio-psychophysiological studies have provided significant answers on the cognitive and perceptive mechanisms, on human movement and on the anticipatory and simulation capabilities of our brain.

These contributions have affirmed, directly and indirectly, a re-evaluation of the different forms of movement activities as tools for the training and opportunities for personal expression of children, who explore reality, learn to organize their experiences through actions. Sensory stimulation and physical activities in daily life, however, are less and less frequent, with negative effects on the individual and social health and well-being.

\section{PHYSICAL INACTIVITY TREND IN ITALY}

Physical inactivity represents the fourth risk factor of death globally and sedentary lifestyle levels are growing in many Countries with a general impact on the health of the world population and, specifically, with implications on the prevalence of non-communicable diseases (NCDs), responsible for $71 \%$ of deaths globally (WHO, 2010). Cardiovascular diseases are the cause of the majority of deaths from NCDs, followed by cancers, respiratory diseases and diabetes; among the behaviours predisposing to an increased risk of 
contracting these diseases, together with the use of tobacco, the harmful use of alcohol and to unhealthy diets, the worrying levels of physical inactivity of the world population emerge.

The reduction of physical activity is a phenomenon that affects the world population at all ages (developmental age, adulthood and third age) whose effects do not only concern the predisposition to risk factors for health but also more generally well-being and good individual bio-psycho-social functioning. A sedentary lifestyle, unfortunately, no longer affects adults and the elderly, but it is an unhealthy habit that emerges more and more precociously, also extending to children and adolescents. In fact, during the developmental age we observe alarming trends of involution of motor skills with a general trend of reduction in the quality and quantity of movements in both children and adolescents; over the last fifty years, unfortunately, the coordination of school-age children has regressed, with a significant delay in the development of coordination especially in urban populations, as well as being affected by a serious and widespread problem of overweight and obesity in childhood.

Since 2007, Italy has a National surveillance system, "OKkio alla SALUTE" (LoOK to the Health), which allows for an accurate estimation of childhood obesity, as well as indirectly evaluating the prevention interventions adopted to combat this phenomenon, including physical activity. "OKkio alla Salute" is closely linked to the Childhood Obesity Surveillance Initiative (COSI) of the WHO European Region, it represents an excellent example of an evidence-based approach that involve the different sector (Health, policy, education) represented by the Ministry of Health and the National Institute of Health, the Regions, the Ministry of Education, University and Research and the school institutions. The first survey revealed worrying data on the health and physical activity levels of children, therefore initiatives were promoted to raise awareness of the problem and take action to combat lifestyles that are harmful to health and well-being. The data that emerged from the last survey of 2016 (Nardone et al., 2018a), confirm an improvement trend, however it concerns obesity and some eating habits, which have continued its downward trend; instead, the aspects relating to movement and a sedentary lifestyle are rather unchanged compared to the past and to other Countries (Haga et al., 2018).

For the adolescents the Italian Health Behaviour in School-aged Children study was conducted throughout all Italian Regions on 11, 13 and 15 year-old students attending public schools. The data have been collected every four years since 2002 and they allow for the construction of trends that indirectly describe what has been implemented and what still needs to be done; among the aspects that emerge as most in need of intervention are nutritional habits and physical activity (Nardone et al., 2018b), although they are "historical" indicators collected by the HBSC, they are still very far from the recommended standards.

Effectively promoting lifestyle changes is a notoriously long process that requires a joint effort from society, school, politics and the individuals themselves who must feel an active part of the change. Physical and sports education programs should be addressed at children and adolescents in an incremental way and, if appropriately designed and conducted, they may become a relevant aspect of life with endpoints related to both physical health and cognitive achievements (Tortella et al., 2017).

\section{ADAPTATIONS FOR CHILDREN AND YOUTH}

During childhood and adolescence, physical activity (as spontaneous movement activities, games, sports, etc.) is necessary for the psychophysical development of the child. Considering the alternation of the phases of stature and weight growth and the biological maturation process of the organic systems, the child develops the motor milestones in the first 5-6 years; starting from these motor milestones in the following years he 
develops specific motor skills, simultaneously with the consolidation of functional prerequisites for motor learning, motor control and senso-perceptive motor adaptation. In fact, throughout childhood, up to the age of 10-12, the child is engaged in structuring the fundamental conditions that allow movement, both on a morphological-functional and cognitive level. The systems involved in movement, in particular the nervous and musculoskeletal systems, are particularly plastic and sensitive to environmental interventions that should be oriented to define a clearer knowledge, perception and consciousness of the body, to develop sensorymotor coordination (both at the general and segmental level), space-time organization, balance and lateralization (Sgrò et al, 2017, 2019).

In the period of adolescence, the sensitive psychophysical changes that occur (Russo et al., 2019) raise the need to rebuild the body schema, verifying and reconstructing the relationship of the body with space and time. Working on the qualitative aspects of the movement is placed in a relationship of reciprocity with the effects on the physical condition of the subject; the frequency, duration and intensity of the activities not only improve the effectiveness of the gesture and the adaptability of motor responses, but also stimulate the parameters of physical efficiency, cardiovascular endurance, strength, speed and joint mobility. During the adolescent phase, it is also crucial to work on the development of social skills and civic sense; for this purpose, physical and sports activities, especially in team play, imply respect for rules, the assumption of roles, the application of technical and tactical schemes. In fact, in the teaching of motor and sports activities it is important to propose wide-ranging experiences, as in this age group, we have to consider the change of interests, the commitment required by studies, the difficulty in meeting expectations, the lack of fun and sociability sport drop-out which aggravates the already serious problem of sedentary lifestyle among young people of the "digital generation". In order to promote active lifestyles to which young people as individuals and as a community are attracted, it is also necessary to take into due consideration the new trends with respect to physical-motor and sports practice and the deconstructed activities that take place also outdoor (Monti, 2019; Notarnicola, 2012).

Promoting physical activity and sports practice to contrast the overflow physical inactivity and sedentary lifestyle of the young population is an even more wonderful goal if it is addressed to children and adolescents with chronic diseases or with disabilities who, unless specific contraindications, should be oriented with the right information for the daily practice of physical activity, for the safe practice of a sport and encouraged to carry out activities chosen on the basis of personal inclinations and desires.

\section{CONCLUSIONS}

Movement needs vary from one population group to another, just as the forms, ways and levels of intensity in which physical activity can be practiced are many and different based on various factors (personal, cultural, environmental, social, economic, etc.). Therefore, the promotion of physical-motor activity represents a complex challenge that must take into account the impact of the choices made in different sectors (health, education, sport, culture, transport, urban planning, economy) and which can determine the success or the failure of actions of prevention and promotion of health and wellbeing aimed at encouraging physical activity in the population.

Starting from the awareness of the importance that physical activity assumes for the general population and of the need for everyone to be able to practice physical activity, using approaches that take into account the different needs and inclinations, physical activity should become a component of daily life that helps to manage and improve the quality of life. 


\section{REFERENCES}

Altavilla, G., Furino, F., Marika, D.P., Raiola, G. (2015). Physical skills, sport learning and socio-affective education [Fizičke vještine, sportsko učenje I društveno-afektivno obrazovanje]Sport Science, 8, pp. 44-46.

Ausubel, D. (2004). Educazione e processi cognitivi. Guida psicologica per gli insegnanti. Milano: Franco Angeli.

Dewey, J. (1961). Democrazia ed educazione (Democracy and Education: an introduction to the philosophy of education). Firenze: La Nuova Italia.

Di Domenico, F., Fattore, S., D'Isanto, T. (2019a). The movement: Complexity and reductionism, evidence in comparison. Journal of Human Sport and Exercise, 14 (Proc4), pp. 1-8. https://doi.org/10.14198/ihse.2019.14.Proc4.18

Di Domenico, F., Fattore, S., Pignato, S., D'Isanto, T. (2019b). Relationship between motor learning and reaction capacity in motor task. Journal of Human Sport and Exercise, 14 (Proc4), pp. S1030-S1037. https://doi.org/10.14198/ihse.2019.14.Proc4.65

Di Domenico, F., D'isanto, T., Raiola, G. (2019c). Role of speed and agility in the effectiveness of motor performance. Journal of Physical Education and Sport, 19, art. no. 271, pp. 1836-1842.

D'Isanto, T. (2019). State of art and didactics opportunities of physical education teaching in primary school. Journal of Physical Education and Sport, 19, art. no. 257, pp. 1759-1762.

D'Isanto, T. (2016). Pedagogical value of the body and physical activity in childhood [Article@Pedagoška vrijednost tijela i tjelesne aktivnosti udjetinjstvu] Sport Science, 9, pp. 13-18.

Elia, F.D., Domenico, F.D., Isanto, T.D., Altavilla, G., Raiola, G. (2020). From biomechanics to motor learning, Acta Medica Mediterranea, 36 (5), pp. 3073-3078.

Gaetano, A. (2016). Relationship between physical inactivity and effects on individual health status, Journal of Physical Education and Sport, 16, pp. 1069-1074.

Gaetano, R. (2012). Motor learning and didactics into physical education and sport documents in middle school-first cycle of education in Italy, Journal of Physical Education and Sport, 12 (2), pp. 157-163.

Gardner H. (1983). Frames of Mind: The Theory of Multiple Intelligences. New York: BasicBooks.

Giovanni, E., Francesca, D., Gaetano, R. (2020). A method to promote the development of intelligence and game skills in youth football, Teoria ta Metodika Fizicnogo Vihovanna, 20 (3), pp. 142-148. https://doi.org/10.17309/tmfv.2020.3.03

Goleman D. (1995). Emotional intelligence. New York: Bantam Books.

Haga, M., Tortella, P., Asonitou, K., Charitou, S., Koutsouki, D., Fumagalli, G., \& Sigmundsson, H. (2018). Cross-cultural aspects: Exploring motor competence among 7-to 8-year-old children from Greece, Italy, and Norway. Sage open, 8(2). https://doi.org/10.1177/2158244018768381

Invernizzi, P.L., Signorini, G., Bosio, A., Raiola, G., Scurati, R. (2020). Validity and reliability of selfperception-based submaximal fitness tests in young adult females: An educational perspective, Sustainability (Switzerland), 12 (6). https://doi.org/10.3390/su12062265

Merleau Ponty, M. (2003). Fenomenologia della percezione. Milano: RCS Libri.

Monacis, D., Colella, D. (2020). Active snacks for the promotion of physical activity in Southern Italy: Preliminary results. Journal of Physical Education and Sport, 20(5), pp. 2665-2670, 363.

Montessori, M. (1950). La scoperta del bambino. Milano: Garzanti Monti, F., Farné, R., Crudeli, F., Agostini, F., Minelli, M., Ceciliani, A. (2019) The role of Outdoor Education in child development in Italian nursery schools, Early Child Development and Care, 189 (6), pp. 867-882. https://doi.org/10.1080/03004430.2017.1345896

Nardone P., Spinelli A., Buoncristiano M., Lauria L., Pierannunzio D., Galeone D. (2018a). II Sistema di sorveglianza OKkio alla Salute: risultati 2016. Roma: Istituto Superiore di Sanità. 
Nardone P., Pierannunzio D., Donati S., Spinelli A., Pizzi E., Ciardullo S., Andreozzi S., Cavallo F., Vieno A., Lazzeri G., Dalmasso P., Borraccino A., Charrier L., Lemma P., Canale N., Lenzi M., Marino C., Simi R., Cappello N., Galeone D. (2018b). Adolescent health behaviours in Italy 2018: HBSC - Health Behaviour in School-aged Children survey. Bollettino epidemiologico nazionale, Roma: Istituto Superiore di Sanità.

Notarnicola, A., Vicenti, G., Fischetti, F., Laricchia, L., Guastamacchia, R., Tafuri, S., Moreti, B. (2012) Improved mental representation of space in beginner orienteers, Perceptual and Motor Skills, 114 (1), pp. 250-260. https://doi.org/10.2466/03.04.11.PMS.114.1.250-260

Novak, J. (2001). L'apprendimento significativo. Le mappe concettuali per creare e usare la conoscenza. Trento: Erickson.

Patrizia, T., Guido, F., Roberto, C., Rosaria, S., Salvatore, P. (2019). The role of the educator/adult in supporting children of pre-school age in learning difficult tasks: The case of the playground "primo sport 0246". Journal of Physical Education and Sport, 19.

Piaget, J. (1972). Lo sviluppo mentale del bambino. Torino: Einaudi. Raiola, G. (2020a). Proposal of rearrangement of physical training and sport sciences methodology academic disciplines in Italian university body. Sport Science, 14 (1), pp. 43-47.

Raiola, G. (2020b). The Movement and Sport Science in Italy towards the European Research Council, Physical Culture and Sport, Studies and Research, 86 (1), pp. 37-48. https://doi.org/10.2478/pcssr2020-0011

Raiola, G., Domenico, F.D., Isanto, T.D., Altavilla, G., Elia, F.D. (2020c). Biomechanics core, Acta Medica Mediterranea, 36 (5), pp. 3079-3083.

Raiola, G., D'Elia, F., Altavilla, G. (2018). Physical activity and sports sciences between European Research Council and academic disciplines in Italy, Journal of Human Sport and Exercise, 13, pp. S283-S295. https://doi.org/10.14198/ihse.2018.13.Proc2.13

Raiola, G. (2017). Motor learning and teaching method, Journal of Physical Education and Sport, 17, art. no. 236, pp. 2239-2243.

Raiola, G. (2013). Body knowledge and motor skills, Knowledge Cultures, 1 (6), pp. 64-72.

Russo, G., Nigro, F., Raiola, G., Ceciliani, A. (2019). Self-esteem in physically active middle school students, Journal of Physical Education and Sport, 19, pp. 1984-1988.

Sgrò, F., Quinto, A., Platania, F., Lipoma, M. (2019). Assessing the impact of a physical education project based on games approach on the actual motor competence of primary school children, Journal of Physical Education and Sport, 19, pp. 781-786.

Sgrò, F., Quinto, A., Messana, L., Pignato, S., Lipoma, M. (2017). Assessment of gross motor developmental level in italian primary school children, Journal of Physical Education and Sport, 17 (3), art. no. 192, pp. 1954-1959.

Tiziana, D., Antonetta, M., Gaetano, A. (2017). Health and physical activity [Zdravlje i tjelesna aktivnost] Sport Science, 10 (1), pp. 100-105.

Tortella, P., \& Fumagalli, G. (2017). The effect of teaching methodologies in promoting physical and cognitive development in children. Physical Activity and Educational Achievement: Insights from Exercise Neuroscience, 297, 303-316. https://doi.org/10.4324/9781315305790-17

World Health Organization (2001). International classification of functioning, disability and health : ICF. World Health Organization.

World Health Organization (2010). Global recommendations on physical activity for health. World Health Organization. 


\section{(c) (1) (9)}

This work is licensed under a Attribution-NonCommercial-NoDerivatives 4.0 International (CC BY-NC-ND 4.0). 